\title{
Nose Blowing for Side Force Control on Slender Cones at High Incidence
}

\author{
Rajan Kumar* and P. R. Viswanath \\ National Aerospace Laboratories, Bangalore 560 017, India \\ and \\ O. N. Ramesh \\ Indian Institute of Science, Bangalore 560 012, India \\ DOI: $\underline{10.2514 / 1.33748}$
}

\begin{abstract}
Vortex asymmetry on axisymmetric pointed forebodies at high angles of incidence results in side forces and adverse yawing moments even in symmetric flight. An experimental investigation has been carried out at low speeds to study the effectiveness of axial nose blowing against the oncoming flow for side force control on two slender cones. Tests were made on the 8 and 12 deg cone models with (circular) jet flow over a Reynolds number range of $0.4 \times 10^{6}$ to $5.4 \times 10^{6}$. Jet-to-freestream velocity ratio was varied up to 2.0 , and the blowing diameter was varied as well. Force measurements were carried over the incidence range of 0 to $45 \mathrm{deg}$, and limited surface pressure distributions were obtained on the $12 \mathrm{deg}$ cone model. The results explicitly show the effectiveness of nose blowing for side force control over a wide range of Reynolds numbers, and minimum side force was reached around a jet velocity ratio of 1.0. An important result is that the side force reduction correlates with jet velocity ratio in the range of parameters studied. Broad similarities in the trend of side force reduction with the nose blowing and the nose bluntness suggest that the interaction of axial jet with freestream flow results, possibly, in what we may call "fluid dynamic blunting."
\end{abstract}

\section{Nomenclature}

$\begin{array}{ll}A_{b} & =\text { cone base area, } \pi / 4 D^{2} \\ A_{J} & =\text { jet area, } \pi / 4 d_{J}^{2} \\ C_{m} & =\text { jet mass flow ratio, } m_{J} / m_{\infty} \\ C_{N} & =\text { normal force coefficient, normal force } / q_{\infty} A_{b} \\ C_{P} & =\text { static pressure coefficient, }\left(p-p_{\infty}\right) / q_{\infty} \\ C_{S} & =\text { side force coefficient, side force } / q_{\infty} A_{b} \\ C \mu & =\text { jet momentum ratio, } m_{J} U_{J} / m_{\infty} U_{\infty} \\ D & =\text { cone base diameter }(=160 \mathrm{~mm}) \\ d_{J} & =\text { jet diameter } \\ M_{\infty} & =\text { freestream Mach number } \\ m_{J} & =\text { jet mass flow rate, } \rho_{J} U_{J} A_{J} \\ m_{\infty} & =\text { reference mass flow rate, } \rho_{\infty} U_{\infty} A_{b} \\ p & =\text { local static pressure } \\ p_{J} & =\text { jet pressure } \\ p_{\infty} & =\text { freestream static pressure } \\ q_{\infty} & =\text { freestream dynamic pressure } \\ R_{D} & =\text { Reynolds number based on base diameter, } \\ & =\rho_{\infty} U_{\infty} D / \mu \\ r_{N} & =\text { nose radius } \\ U_{J} & =\text { jet velocity } \\ U_{\infty} & =\text { freestream velocity } \\ V_{J} & =\text { volumetric flow rate of jet } \\ U_{J} / U_{\infty} & =\text { jet velocity ratio } \\ \alpha & =\text { angle of incidence, deg } \\ \alpha_{o} & =\text { angle of incidence corresponding to vortex } \\ \Delta C_{N} & =\text { asymmetry onset, deg } \\ \Delta C_{P} & =\text { uncertainty in normal force coefficient } \\ & \end{array}$

Received 27 July 2007; revision received 4 February 2008; accepted for publication 5 February 2008. Copyright $\odot 2008$ by Rajan Kumar. Published by the American Institute of Aeronautics and Astronautics, Inc., with permission. Copies of this paper may be made for personal or internal use, on condition that the copier pay the $\$ 10.00$ per-copy fee to the Copyright Clearance Center, Inc., 222 Rosewood Drive, Danvers, MA 01923; include the code 0021-8669/08 \$10.00 in correspondence with the CCC.

*Scientist, National Trisonic Aerodynamic Facilities; currently Research Scientist, Advanced Aero-Propulsion Laboratories, Florida State University, Tallahassee, FL 32310. Member AIAA.

${ }^{\dagger}$ Head, Experimental Aerodynamics Division. Associate Fellow AIAA.

${ }^{\ddagger}$ Assistant Professor, Department of Aerospace Engineering.

$\begin{array}{ll}\Delta C_{S} & =\text { uncertainty in side force coefficient } \\ \theta_{C} & =\text { semi-apex cone angle, deg } \\ \rho_{J} & =\text { jet flow density } \\ \rho_{\infty} & =\text { freestream density } \\ \phi & =\text { circumferential angle, deg } \\ \psi & =\text { roll position, deg } \\ 2 r_{N} / D & =\text { bluntness ratio }\end{array}$

\section{Introduction}

$\mathbf{M}$ ODERN fighter aircraft and missiles are expected to perform post-stall maneuverability to achieve tactical advantages. This can result in flight at high angles of attack (up to 45-50 deg) and knowledge of the nonlinear aerodynamics, including strong viscous effects leading to crossflow separation, becomes very important in the design of a flight vehicle. One of the important problems, which has received considerable attention (e.g., Hunt [1] , Ericsson and Reding [2] , Champigny [3] , and Williams [4]]) during the last two decades, is the phenomenon of vortex asymmetry on pointed forebodies at high angles of attack and the resulting side forces and adverse yawing moments, even in symmetric flight (zero side slip): the yawing moments generated are often too large to be controlled by using the rudder power in the case of a fighter aircraft. The major geometric parameters that are known to influence vortex asymmetry include nose apex angle, forebody cross-sectional shape, and fineness ratio of the slender body. The side forces generated are strongly Reynolds number dependent, and the effects gradually decrease with increase in flight Mach number; the problem is essentially predominant at low to subsonic speeds in which high alpha maneuvers normally occur.

Because the adverse yawing moments can be very large and also difficult to predict even in an engineering sense, there have been several attempts to reduce or even alleviate these undesirable side forces by both passive and active flow control techniques. These include different kinds of nose strakes [5-9], boundary layer trips $[6,10,11]$, nose blunting $[6,12,13]$, and nose tip rotation [14], and the beneficial effects of many of the previously mentioned devices have been demonstrated over a limited range of flow parameters like Mach number and Reynolds number. Recently, Rajan Kumar et al.[15] carried out a systematic parametric study of nose bluntness on two slender cones for side force control covering a wide range of 